\title{
An exploratory study of the resilience of manufacturing in the Cardiff Capital Region
}

\author{
Anthony Soroka ${ }^{1}$, Mohamed Naim ${ }^{1}$, Gillian Bristow ${ }^{2}$, Laura Purvis ${ }^{1}$ \\ ${ }^{1}$ Cardiff Business School, Cardiff University, Cardiff, CF10 3EU, UK \\ SorokaAJ@cf.ac.uk, NaimMMQcf.ac.uk, PurvisL@cf.ac.uk \\ ${ }^{2}$ School of Planning and Geography, Cardiff University, Cardiff, CF10 3WA, UK \\ BristowGlecf.ac.uk
}

\begin{abstract}
Sustainability in all its guises is important for the long term continuance of manufacturing. The ideas of local sustainability and resilience have become increasing popular topics for study. The drive for economic resilience is causing governments to look at regional strategies to improve economic sustainability and resilience. A recent example of this is the establishment of a Cardiff Capital Region (CCR) in Wales. This exploratory study takes an initial look at the resilience of manufacturing in the CCR vis-à-vis economic resilience using the FAME dataset and QuiScore measure. Results indicate that on the whole manufacturing looks broadly healthy. However, some potential areas of concern were identified, many of the biggest and healthiest companies are not headquartered in the CCR, whereas $98 \%$ of the weakest companies are, and there are inter and intra sectorial differences. The study also suggests that measures such as QuiScore should perhaps not be used in isolation as its methodology is unknown and a large number of companies do not have QuiScores.
\end{abstract}

Keywords: sustainability, resilience, QuiScore, manufacturing

\section{Introduction}

Shaw \& Newby in their exploration of local economic development define sustainability as "the capacity for continuance more or less indefinitely into the future"[1]. As such it incorporates the many facets of sustainability, economic, environmental, and social etc. Many definitions exist, Bonevac states that there are over 300 definitions in literature, going as far as to say that "Devising criteria and measures of sustainability has become a cottage industry"[2].

In order to be sustainable the manufacturing sector also needs to have resilience: "the ability of a system to return to its original state or move to a new, more desirable state after being disturbed"[3]. Specifically a firm's vulnerability / capacity to survive and adapt, resist decline and respond to opportunities[4]). Allied to this is the concept of regional resilience which has

adfa, p. 1, 2011.

(c) Springer-Verlag Berlin Heidelberg 2011 
emerged as a trend that is developing a widespread appeal, in particular when examining how regions have fared during the recent economic crisis[5].

Government are paying increased attention to regions, in autumn 2011, the Welsh Government's Minister for Business, Enterprise, Technology established a Task and Finish Group to consider the evidence for city regions as economic drivers, and to identify potential city regions in Wales. As a result of this in November 2013 Cardiff Capital Region (CCR) Board was established, with confirmation of $£ 580$ million of funding announced by the Welsh Government in November 2015. The CCR incorporates the following authorities: Blaenau Gwent; Bridgend; Caerphilly; Cardiff; Merthyr Tydfil; Monmouthshire; Newport; Rhondda Cynon Taff; Torfaen; and The Vale of Glamorgan.

This exploratory study aims to examine the manufacturing resilience of the CCR using the QuiScore provided within the FAME database, and investigate any potential impact this could have on the resilience of manufacturing within CCR. The paper is structured as follows: a description of the QuiScore together with examples of its application is provided, followed by an investigation of the manufacturing sector in the CCR, a more detailed investigation of several sectors, and finally the conclusions.

\section{QuiScore}

\subsection{QuiScore Description}

The QuiScore was originally developed by Qui Credit Assessment Ltd [6] and now provided by CRIF Decision Solutions [7] is a measure of the likelihood of a particular company failing within the 12 months period following the date of calculation. According to Bureau van Dijk the publishers of the FAME database, the QuiScore is calculated using statistical and modelling techniques to select and apply a weight to data elements (variables and coefficients) that are most predictive of business failure[8].

In information provided to subscribers to the FAME database, Bureau van Dijk explain that the data used to generate QuiScores are extracted from the following areas of company information:

- Account information

- Profitability

- Solvency

- Leverage

- Business structure

- Capitalisation

- Working capital 
- Cash flow

- Liquidity

- Productivity

- Trend

- Director history

- Registry Trust Information: County Court Judgements (CCJs)

- Shareholder funds

- Lateness in filing accounts

All this information is included during the process that evaluates the QuiScore, taking into consideration the medium-term life cycle of the company as a whole. With the selection of variables and application of weightings to them claimed to be the result of extensive data analysis. The development of calculation models considers a combination of the "good" and "bad" performance of businesses held in the source database.

According to Bureau van Dijk the QuiScore, is provided as a number within the range $0-100$, with 0 representing those companies with the highest likelihood of failure. As shown in Table 1 the scores have been divided into five distinct bands.

Table 1. QuiScore Bands. (Source: Bureau van Dijk)

\begin{tabular}{l|l}
\hline Qui Band & Description \\
\hline 81-100 Secure & $\begin{array}{l}\text { Companies in this band tend to be large and successful } \\
\text { public companies. Failure is very unusual and normally } \\
\text { occurs only as a result of exceptional changes within the } \\
\text { company or its market. }\end{array}$ \\
\hline 61-80 Stable & $\begin{array}{l}\text { Company failure is a rare occurrence and will only come } \\
\text { about if there are major company or marketplace changes }\end{array}$ \\
\hline 41-60 Normal & $\begin{array}{l}\text { This band contains many companies that do not fail, but } \\
\text { some that do. }\end{array}$ \\
\hline 00-20 High Risk & $\begin{array}{l}\text { As the name suggests, there is a significant risk of compa- } \\
\text { ny failure; in fact, companies in this band are, on average, } \\
\text { four times more likely to fail than those in the Normal Band. }\end{array}$ \\
& $\begin{array}{l}\text { Companies in the High Risk sector may have difficulties in } \\
\text { continuing trading unless significant remedial action is un- } \\
\text { dertaken, there is support from a parent company, or spe- } \\
\text { cial circumstances apply. A low score does not mean that } \\
\text { failure is inevitable. }\end{array}$ \\
\hline
\end{tabular}

Bureau van Dijk expands upon this information by providing the percentage of likelihood of failure based on the QuiScore range as shown in Table 2 . 
Table 2. QuiScore Likelihood of Failure. (Source: Bureau van Dijk)

\begin{tabular}{l|l}
\hline QuiScore range & Percentage likelihood of failure \\
\hline $00-10$ & $100.00 \%$ \\
$11-20$ & $50.00 \%$ \\
$21-30$ & $29.00 \%$ \\
$31-40$ & $11.00 \%$ \\
$41-50$ & $6.00 \%$ \\
$51-60$ & $1.00 \%$ \\
$61-100$ & $0.00 \%$ \\
\hline
\end{tabular}

\subsection{QuiScore in Research}

Within academic research literature the QuiScore is used in a variety of ways, a common application is to the assessment of the strength of individual companies, such as rating of credit risks[9], or assessing the strength of companies[7]. These are the sorts of applications that one would expect to see from a credit risk measure.

Some studies have used QuiScores to examine other factors for either individual companies or groups of companies. Examples of this include examining whether there is an association between the number of risk disclosures by companies and a variety of risk measures[10], how a firms' level of global engagement is reflected in their financial health[11], the impact of private equity on innovation activities, and the links between financial health and exporting[12]. This use of the QuiScore to examine both individual companies as well as groupings suggests that its use in examining manufacturing in the CCR is an appropriate technique. This conclusion is further strengthened by it being used in the identification, for further evaluation, of companies in the forging sector within the West Midlands area in the UK[13].

Of note is that the proprietary nature of the QuiScore has been noticed which has encouraged research that is aimed at replicating the QuiScore method[14].

\section{Analysis of economic resilience of CCR}

The FAME dataset was interrogated in September 2015 using the search criteria shown in Table 3. This resulted in 2607 companies being identified, once all companies without a current QuiScore and a non-manufacturing primary SIC were eliminated this was reduced down to 1796 . 
Table 3. FAME search criteria

\begin{tabular}{l|l}
\hline Criteria & Value \\
\hline Company status & All active companies \\
Location & CF \& NP postal regions (all trading addresses) \\
Industry & $10000-32990$ UK SIC (2007) \\
\hline
\end{tabular}

\subsection{Overall manufacturing resilience}

In order to the investigate the overall economic strength of the CCR the QuiScores need to be examined. The study examines, all companies, the top and bottom companies (by turnover figure provided in FAME), and the companies with no turnover (those which by law are not required to report one).

Table 4. Average QuiScores for CCR manufacturing

\begin{tabular}{l|l|l|l}
\hline & Average Type & Value & Qui Risk \\
\hline All & Mean $(\sigma)$ & $53.50(25.24)$ & Normal \\
& Mode & 50.00 & Normal \\
& Median & 50.00 & Normal \\
\hline Top 50 & Mean $(\sigma)$ & $86.06(12.40)$ & Secure \\
& Mode & 94.00 & Secure \\
& Median & 90.00 & Secure \\
\hline Top 100 & Mean $(\sigma)$ & $87.74(10.55)$ & Secure \\
& Mode & 90.00 & Secure \\
& Median & 91.00 & Secure \\
\hline Top 250 & Mean $(\sigma)$ & $88.07(12.19)$ & Secure \\
& Mode & 94.00 & Secure \\
& Median & 92.00 & Secure \\
\hline Bottom 100 & Mean $(\sigma)$ & $62.20(25.54)$ & Stable \\
& Mode & 90.00 & Secure \\
& Median & 67.00 & Stable \\
\hline Bottom 50 & Mean $(\sigma)$ & $48.47(24.93)$ & Normal \\
& Mode & 16.00 & High Risk \\
& Median & 48.00 & Normal \\
\hline No Turnover & Mean $(\sigma)$ & $44.29(19.30)$ & Normal \\
& Mode & 50.00 & Normal \\
& Median & 46.00 & Normal \\
\hline
\end{tabular}

The figures shown in Table 4 are positive in that average (mean) QuiScores are all in the Normal or better band. However, a slightly different picture is painted when the data is examined in more detail, especially for those companies in the Bottom 50 or those without turnover. The standard 
deviations are sufficiently large that a significant proportion of them will fall into unstable band. In total 18 of the Bottom 50 companies are Unstable or High Risk), and for the 1357 companies with no recorded turnover 494 are Unstable or High Risk (36\%).

More in-depth analysis of this data was conducted where average turnover, mean \& median numbers of trading addresses were examined. Upon analysis of the data it was noticed that there was one outlier company with several hundred trading address (which manufactured in the CCR), this company was therefore excluded. This data is shown in Table 5.

Table 5. Average QuiScore, Turnover and Trading Addresses

\begin{tabular}{l|l|l|l|l}
\hline & & $\begin{array}{l}\text { Average } \\
\text { Turnover } \\
(£ 000 ' s)\end{array}$ & $\begin{array}{l}\text { Mean } \\
\text { Trading } \\
\text { Addresses }\end{array}$ & $\begin{array}{l}\text { Median } \\
\text { Trading } \\
\text { Addresses }\end{array}$ \\
\hline All & Qui Risk & 165,535 & 2.78 & 1.00 \\
Top 50 & Secure & $1,215,706$ & 23.14 & 16.00 \\
Top 100 & Secure & 663,629 & 19.11 & 5.50 \\
Top 250 & Secure & 285,761 & 12.30 & 2.00 \\
Bottom 100 (with turnover) & Stable & 1,863 & 1.22 & 1.00 \\
Bottom 50 (with turnover) & Normal & 280 & 1.10 & 1.00 \\
No Turnover & Normal & N/A & 1.19 & 1.00 \\
\hline
\end{tabular}

One thing that becomes apparent from looking at Table 5 is that there is strong evidence suggesting that the top companies in CCR (in terms of turnover) are national or multi-national primarily due to the number of trading addresses a company might have. The mean number of addresses is over 23 for the Top 50 companies, as already noted in this study this average can be skewed by having several companies with a large number of locations (for example a manufacturer that also retails). Examination of the Median gives a value of 16 , which confirms that a significant proportion of these companies have more than one or two trading addresses.

Whilst the overall QuiScore is high and these top companies are considered to be secure, which is positive, the number of trading locations could be cause for concern. Especially if the registered office isn't in the region, a trend within supply chain management is that of re-shoring, so such a company might be tempted to have manufacturing closer to the head office. Referring back to the FAME data for the Top 50 companies in the CCR it was discovered that only 9 of the 50 have their registered office in the CCR ( 3 of which in the same group of companies). When FAME data is examined for companies with a QuiScore $\leq 10$, only 2 of 108 have their $\mathrm{HQ}$ outside the CCR. This suggests that weaker companies may have stronger links to the 
communities they are based in, which could be both positive and negative from the perspective of sustainability and resilience of a particular community.

\subsection{Sectorial resilience}

The average, minimum and maximum QuiScore, and standard deviation of the average to $-/+\sigma$ for each manufacturing sector based on the UK SIC (Standard Industrial Classification) codes are shown in Fig. 1

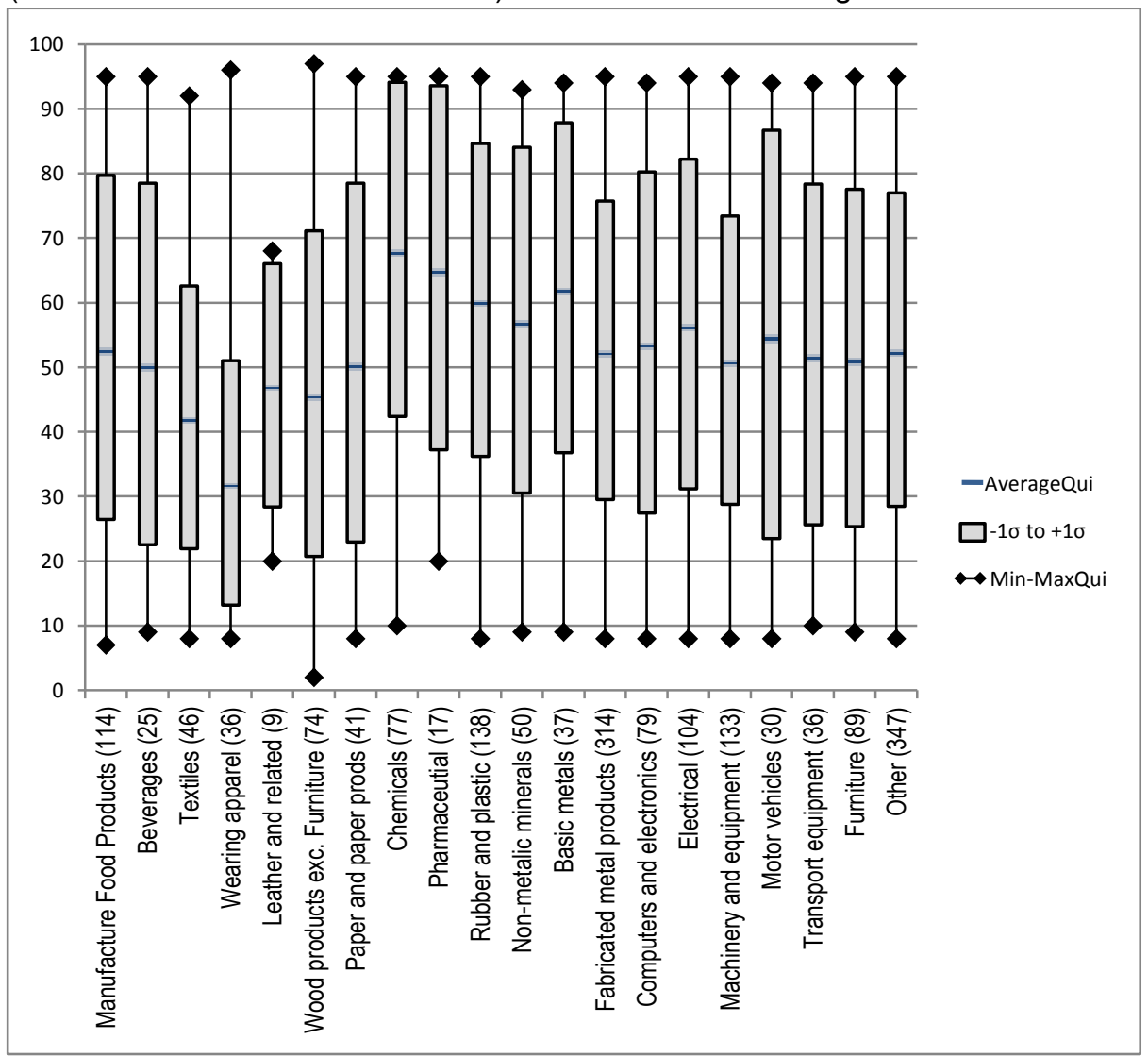

Fig. 1. QuiScore of Industrial Sectors (number of companies in sector) in CCR

Broadly speaking the sectors look similar. However, there are two sectors that are particularly interesting. Firstly Chemicals, it has highest average QuiScore $(\bar{x}) 68.3$, highest $\bar{x}-\sigma$ and highest $\bar{x}+\sigma-$ so much so that all within range are above 40 and hence are in the Normal band or better. Secondly Wearing apparel, it has lowest average QuiScore $(\bar{x}) 32.1$, the lowest $\bar{x}-\sigma$ and lowest $\bar{x}+\sigma$. The following section examines these two sectors in more detail. 


\section{Chemicals Sector.}

The average QuiScores of the sub-sectors are shown below in Table 6, as can be seen they generally fall into the Stable or Secure bands. The only sub-sector that doesn't is the manufacture of soaps and detergents, although it is still in the Normal band. This sub-sector has a large discrepancy between poor performing companies seven of the twelve companies have a QuiScore below 40 , whilst the remaining five have a score over 50 .

Table 6. Chemicals sub-sectors

\begin{tabular}{l|l}
\hline Sub-sector & $\begin{array}{l}\text { Average } \\
\text { QuiScore }\end{array}$ \\
\hline 201. Manufacture of basic chemicals, fertilisers and nitrogen \\
compounds, plastics and synthetic rubber in primary forms \\
202. Manufacture of pesticides and other agrochemical products & 75.43 \\
203. Manufacture of paints, varnishes and similar coatings, & 61.00 \\
printing ink and mastics & 70.80 \\
204. Manufacture of soap and detergents, cleaning and polish- & 48.67 \\
ing preparations, perfumes and toilet preparations & \\
205. Manufacture of other chemical products & 68.33 \\
\hline
\end{tabular}

Further examination of data from FAME for the sector shows that the companies with the highest QuiScore have their registered offices both inside and outside of the CCR. However, those with the lowest QuiScore are registered in the CCR. Additionally many these companies have had poor QuiScores for several years. This does raise a question about whether they might be trapped in a vicious cycle where because of the low QuiScore tier 1 or 2 suppliers may not be willing to use them.

\section{Wearing Apparel.}

The average QuiScores of the sub-sectors are shown below in Table 7, both of the sub-sectors fail to fall into the Normal band.

Table 7. Wearing Apparel sub-sector

\begin{tabular}{l|l}
\hline Sub-sector & AverageQui \\
\hline 141. Manufacture of wearing apparel, except fur apparel & 32.46 \\
143. Manufacture of knitted and crocheted apparel & 20 \\
\hline
\end{tabular}

Further examination of data from FAME for the sector shows that the company with the highest QuiScore (and the only company within the Secure band) has their registered offices outside of the CCR. However, those with the lowest QuiScore are registered in the CCR. Despite this these low 
QuiScores there are several example of companies trading for at least ten years with QuiScores in the 15-25 (High Risk - Unstable) range. This is something that is very different to the Chemical sector where no companies have been able to sustain such poor scores for ten years or more. This suggests that something else might be occurring that helps keep these companies afloat - perhaps a sectorial or regional resilience aided by social networks or lower regulation/overheads.

\section{Conclusions}

Companies based in multiple locations, in particular those whose registered offices are not located in the CCR, may have little attachment to a particular area. This could be negative with regards to resilience and long term sustainability in a region.

There also appears to be a trend that the companies with the lowest QuiScore are based within the CCR. Whereas companies with high score are often based outside of the CCR.

The work has also identified that there are companies, whose poor QuiScores suggest that they should not be in business yet have managed to sustain themselves for extended periods of time. This suggests that there may be other factors involved that this study has not been able to identify. Also there appears to be a sectorial difference in the ability of companies to sustain themselves whilst having poor QuiScores.

\section{$5 \quad$ Limitations and further work}

A limitation of this work is that it only uses the QuiScore, whose method is unknown and as such a large number of companies are excluded from examination. Further studies could potentially benefit from using alternative measures of company wellbeing. Also this work does not examine all of the industrial sub-sectors, also it doesn't examine the historical data of those companies that have been dissolved. Finally due to limitations of the dataset it doesn't look at the interactions between companies, and their supply chains.

As a result of this exploratory study it evident that there there a large number of potential factors that will require further investigation. As a result of this future work will need to address the following issues and questions:

- Mapping of sector v QuiScore v region

- Use of alternative measures

- More analysis of sectors, registered address locations and QuiScores, and the subsequent regional implications 
- Identification of the factors contributing to some sectors being able to sustain poor QuiScores for longer

- Examination of resilience from the regional and sectorial perspectives

- Examination of dissolved companies within the region

\section{$6 \quad$ Acknowledgements}

This work was supported by the EPSRC "Re-Distributed Manufacturing and the Resilient, Sustainable City" (EP/M01777X/1) RDM Network.

\section{$7 \quad$ References}

1. Shaw, P.E., Newby, L.: Sustainable wealth creation at the local level in an age of globalization. Regional studies 32, 863-871 (1998)

2. Bonevac, D.: Is Sustainability Sustainable? Acad. Quest. 23, 84-101 (2010)

3. Christopher, M., Peck, H.: Building the resilient supply chain. International Journal of Logistics Management, The 15, 1-14 (2004)

4. Valikangas, L.: The Resilient Organization: How Adaptive Cultures Thrive Even when Strategy Fails. McGraw-Hill (2010)

5. Bristow, G., Healy, A.: Regional resilience: an agency perspective. Regional Studies 48, 923-935 (2014)

6. Pendlebury, M., Groves, R.E.V., Groves, R.: Company accounts: analysis, interpretation and understanding. Cengage Learning EMEA (2004)

7. Jeffrey, M.: A decade of Alternative Investment Market (AIM) - but little impact on the UK apparel sector. Journal of Fashion Marketing and Management: An International Journal 11, 441-444 (2007)

8. FAME: FAME - Financial Analysis Made Easy. (2015)

9. Baourakis, G., Conisescu, M., van Dijk, G., Pardalos, P.M., Zopounidis, C.: A multicriteria approach for rating the credit risk of financial institutions. Comput Manag Sci 6, 347-356 (2009)

10. Linsley, P.M., Shrives, P.J.: Risk reporting: A study of risk disclosures in the annual reports of UK companies. The British Accounting Review 38, 387-404 (2006)

11. Guariglia, A., Mateut, S.: Inventory investment, global engagement, and financial constraints in the UK: Evidence from micro data. Journal of Macroeconomics 32, 239-250 (2010)

12. Greenaway, D., Guariglia, A., Kneller, R.: Financial factors and exporting decisions. Journal of international economics 73, 377-395 (2007)

13. Mulhall, R.A.: Manufacturing change: competitiveness and adjustment through evolving production relationships. University of Birmingham (2013)

14. Doumpos, M., Pasiouras, F.: Developing and testing models for replicating credit ratings: A multicriteria approach. Computational Economics 25, 327-341 (2005) 